\title{
Uma revisão de conceitos sobre florestas em faxinais com base em uma abordagem fitogeográfica
}

\author{
A review of concepts about faxinal forests through a phytogeo- \\ graphic approach
}

\section{Una revisión de los conceptos sobre los bosques en faxinais a través de un abordaje de la fitogeografia}

\author{
Edson Struminski \\ estruminski@uepg.br \\ Universidade Estadual de Ponta Grossa \\ Juliano Strachulski \\ julianomundogeo@gmail.com \\ Universidade Estadual de Ponta Grossa
}

\begin{abstract}
Resumo: Existe grande quantidade de estudos sobre os faxinais, a maioria sobre aspectos socioeconômicos e culturais deste sistema. Os faxinais geralmente são apresentados como sistemas agroflorestais e pastoris por excelência, com uma ênfase primordial na existência de áreas florestais manejadas, as quais seriam o pressuposto principal da identidade deste sistema. Mesmo assim, ainda são pouco comuns os trabalhos científicos que estudam os aspectos florestais dos faxinais, o que vem gerando desde distorções em políticas públicas, até a incompreensão pelos motivos do desaparecimento desse interessante sistema. Neste trabalho serão apresentados um mapeamento da vegetação de um faxinal e considerações sobre seu manejo e evolução, como forma de avaliar a alegada sustentabilidade desse sistema. Também será apresentada uma revisão de conceitos sobre florestas de faxinais e um debate sobre seus aspectos ecológicos.
\end{abstract}

Palavras-chave: Florestas manejadas. Faxinal. Sustentabilidade. Fitogeografia.

Abstract: There are several studies about faxinais, mainly focused on socio-economical and cultural aspects of the system. Faxinais are usually presented as agroforestry and pastoral par excellence, with a primary emphasis on the existence of managed forest areas, which would be the main assumption about identity of this system. However there are very few who study the scientific aspects of forest faxinais, which has generated from distortions in public policies to misunderstanding the reasons of the disappearance of this interesting system. This paper presents a vegetation mapping of a Faxinal and considerations about its management and development in order to evaluate its alleged system sustainability and its aspects.

Keywords: Forest uses. Faxinal. Sustainability. Phytogeography. 
Resumen: Hay muchos estudios sobre los faxinais, sobre todo en los aspectos socioeconómicos y culturales de este sistema. Los faxinais suelen presentarse como sistemas agroforestales y pastoril por excelencia, con un énfasis primordial en la existencia de áreas forestales gestionadas, lo que sería la principal hipótesis de la identidad de este sistema. Sin embargo, son pocos comunes los trabajos científicos que estudian los aspectos de los bosques faxinais, lo que proviene de las distorsiones que generan en las políticas públicas, a la incomprensión de las razones de la desaparición de este interesante sistema. Este trabajo presenta un mapeo de la vegetación de un faxinal y las consideraciones acerca de su manejo y la evolución, como una forma de evaluar la alegación de sostenibilidad de este sistema. También se presenta una revisión de conceptos sobre los bosques de faxinais y un debate sobre sus aspectos ecológico.

Palabras claves: Bosques Manejados. Faxinal. Sostenibilidad. Fitogeografía.

\section{INTRODUÇÃO}

É opinião corrente que os faxinais são áreas sustentáveis, que mantêm os últimos remanescentes das florestas com Araucaria angustifolia, o pinheiro do Paraná, os quais estariam preservados na sua área original de ocorrência, muito em função dos faxinais.

Mas as dificuldades em sustentar essa afirmação decorrem do entendimento de diferentes pesquisadores para o que seja, de fato, uma floresta primária subtropical como as florestas com Araucaria angustifolia, uma formação estrutural e floristicamente complexa, de grande biodiversidade e hoje já rara, em confronto com os estágios sucessionais secundários desta mesma floresta, estes, na verdade, ambientes mais simples e, de modo geral, predominantes hoje na área rural paranaense, em função da vasta exploração que a floresta primária sofreu nos últimos 100 anos.

Mais difícil ainda tem sido para muitos pesquisadores entenderem que inclusive estas áreas florestais manejadas nos faxinais já não se apresentam estruturalmente intactas ou íntegras, mesmo como estágios sucessionais secundários. A ausência de sub-bosque e o corte seletivo de madeiras fragmentam e empobrecem esse ecossistema, podendo levar o ambiente florestal a uma simplificação, à quebra da sua resiliência e, por fim, ao desaparecimento de muitas das suas funções (por exemplo, controle da erosão, renovação genética ou abrigo de fauna nativa), ainda que sua forma florestal se mantenha, ao menos aparentemente. Em última análise, esse processo destrói também a sustentação econômica do criadouro do faxinal ${ }^{1}$ e dele próprio.

Visando entender a condição florestal dos faxinais, os presentes autores produziram em laboratório e em campo um mapeamento fitogeográfico de um faxinal. Além disso, buscou-se um apoio na revisão bibliográfica dos trabalhos existentes. Constatou-se então

1 O criadouro é entendido como um local de criação de animais em área florestada sob regime de apropriação comunal. É formado por terrenos justapostos de várias famílias que, de forma coletiva, criam seus animais à solta em meio a áreas florestais, também utilizadas para extração de erva-mate (SAHR e CUNHA, 2005). Circunvizinho ao criadouro comunitário está o espaço dos cultivos agrícolas, cujas terras são usadas sob regime de propriedade privada. 
que, na verdade, são escassas as pesquisas sobre aspectos ecológicos de faxinais. Conforme já mencionado, há uma ênfase em estudos socioeconômicos, detectada por um dos autores do presente estudo, após organizar o Portal Faxinais (www.faxinaiswordpress.com), que agrupa 60 trabalhos com produção científica dos últimos 10 anos sobre esse assunto ${ }^{2}$.

De acordo com esse site, apenas 10 \% desta produção corresponde a estudos do meio biológico dos faxinais e somente dois analisam algum aspecto ecológico da floresta sob o sistema faxinal. A maioria dos estudos sobre faxinais é, portanto, voltada para aspectos socioeconômicos e culturais deste sistema e simplesmente desconsidera ou apresenta conceitos inadequados para definir a floresta.

Finalmente, foram confrontados aspectos ecológicos dos faxinais em relação a outros de caráter socioeconômico, para verificar se a hipótese de sustentabilidade desse sistema, defendida por alguns autores, comprova-se ou não.

\section{PROCEDIMENTOS METODOLÓGICOS}

Com o intuito de produzir uma revisão conceitual e parâmetros válidos para a pesquisa florestal em faxinais, foram seguidos alguns procedimentos. Está sendo utilizado o sistema fisionômico-ecológico do IBGE para evitar a não uniformidade terminológica encontrada em trabalhos anteriores sobre faxinais, com termos muitas vezes meramente descritivos (fisionomia) e que dificultam comparações sobre a evolução das alterações na vegetação, como será visto na discussão deste artigo.

Como área de estudo, foi definido o criadouro do faxinal Taquari dos Ribeiros localizado em Rio Azul - PR. Objetivando verificar se, de fato, este tipo de área comporta áreas florestais representativas, como seria a hipótese inicial do estudo e se as áreas florestais ali existentes são sustentáveis.

Para o mapeamento da vegetação da área de estudo, foram realizadas as etapas discriminadas a seguir:

a) Fotointerpretação na escala aproximada de 1: 20.000 (escala detalhada), de cópias em papel de imagens orbitais Imagem Worldview (pancromática) de 2008, resolução espacial de $1 \mathrm{~m}$.

b) Visitas a campo, ocasiões em que percorreram-se áreas representativas das formações tipológicas, para fins de checagem e atualização da fotointerpretação, bem como para caracterização e diagnóstico das tipologias vegetais existentes.

c) Entrevistas com alguns dos faxinalenses mais antigos, com o intuito de entender-se a evolução da cobertura florestal e do uso dos recursos florestais pelos faxinalenses.

d) Elaboração do mapa de vegetação do faxinal, mediante a construção de polígo-

2 O site faxinaiswordpress foi criado com o intuito de produzir um banco de dados especializado que atendesse pesquisadores desta temática, dentro do âmbito do projeto do mestrado em Gestão do Território da UEPG: "Gestão Participativa de Recursos Naturais em Faxinais" (PNPD/CAPES 2008-2012). 
nos no programa Quantum Gis 1.6 Copiapó, com as diferentes tipologias vegetais encontradas.

e) Elaboração de versão definitiva do mapa de vegetação, juntamente com a descrição da vegetação desta região. Esse mapa serviu de base para o diagnóstico da área, com base na fragmentação florestal e para as discussões sobre aspectos ecológicos das áreas florestais dos faxinais.

Finalmente, com base no mapeamento da vegetação, nas entrevistas e a partir de uma revisão bibliográfica dos trabalhos disponíveis no Portal Faxinais Wordpress, foi realizada uma discussão e uma revisão de conceitos sobre florestas em faxinais e sobre a "sustentabilidade" do Sistema Faxinal, confrontando-se a visão de autores da área das ciências humanas frente autores das ciências naturais.

\section{3 ÁREA DE ESTUDO}

O faxinal Taquari dos Ribeiros está localizado na zona rural do município de Rio Azul, centro-sul do Paraná, a aproximadamente $20 \mathrm{~km}$ da área urbana deste município, apresentando uma pequena porção no município vizinho de Irati. Estimou-se para a área do criadouro comum (florestada) aproximadamente 256 ha, por onde correm quatro rios, também denominados de "sangas" pela população local, o Cachoeira, o Taquari, o Rio dos Boles e o Arroio dos Ribeiros (Figura 1), pertencentes à bacia do rio Iguaçu.

Segundo Silva (2010), este faxinal formou-se no início do século XX e abriga atualmente cerca de 120 famílias, com uma população aproximada de 350 habitantes. De acordo com essa autora, o faxinal Taquari está incluído entre os 44 faxinais do Estado do Paraná que ainda apresentam características tradicionais, com criadouro de uso coletivo cercadas com uso restrito para criação e remanescentes da Floresta de Araucária, tendo sido classificado como ARESUR, um formato de unidade de conservação definido pelo governo paranaense para os faxinais.

\section{A VEGETAÇÃO DA REGIÃO DO FAXINAL}

Com base na dispersão florística regional, de Veloso et al (1991), a região onde situa-se o faxinal Taquari dos Ribeiros pode ser enquadrada na "Região Florística do Sudeste", dentro da qual encontramos o "Domínio da Floresta Atlântica", entendendo-se domínio por "área caracterizada por espécies endêmicas". Dentro deste domínio, é possível distinguir ainda classes de formações florestais, sendo que a formação propriamente dita é determinada pelo ambiente (formas de relevo). Uma das formações fitoecológicas definidas pelo IBGE para o Paraná e que ocorre nesta região é a Formação florestal Floresta Ombrófila Mista e vegetação associada, nos seguintes patamares:

- Floresta Montana - de 850 a cerca de 1000 m s.n.m. no planalto. 
Figura 1 - Localização do faxinal Taquari dos Ribeiros na bacia hidrográfica do rio Cachoeira - PR

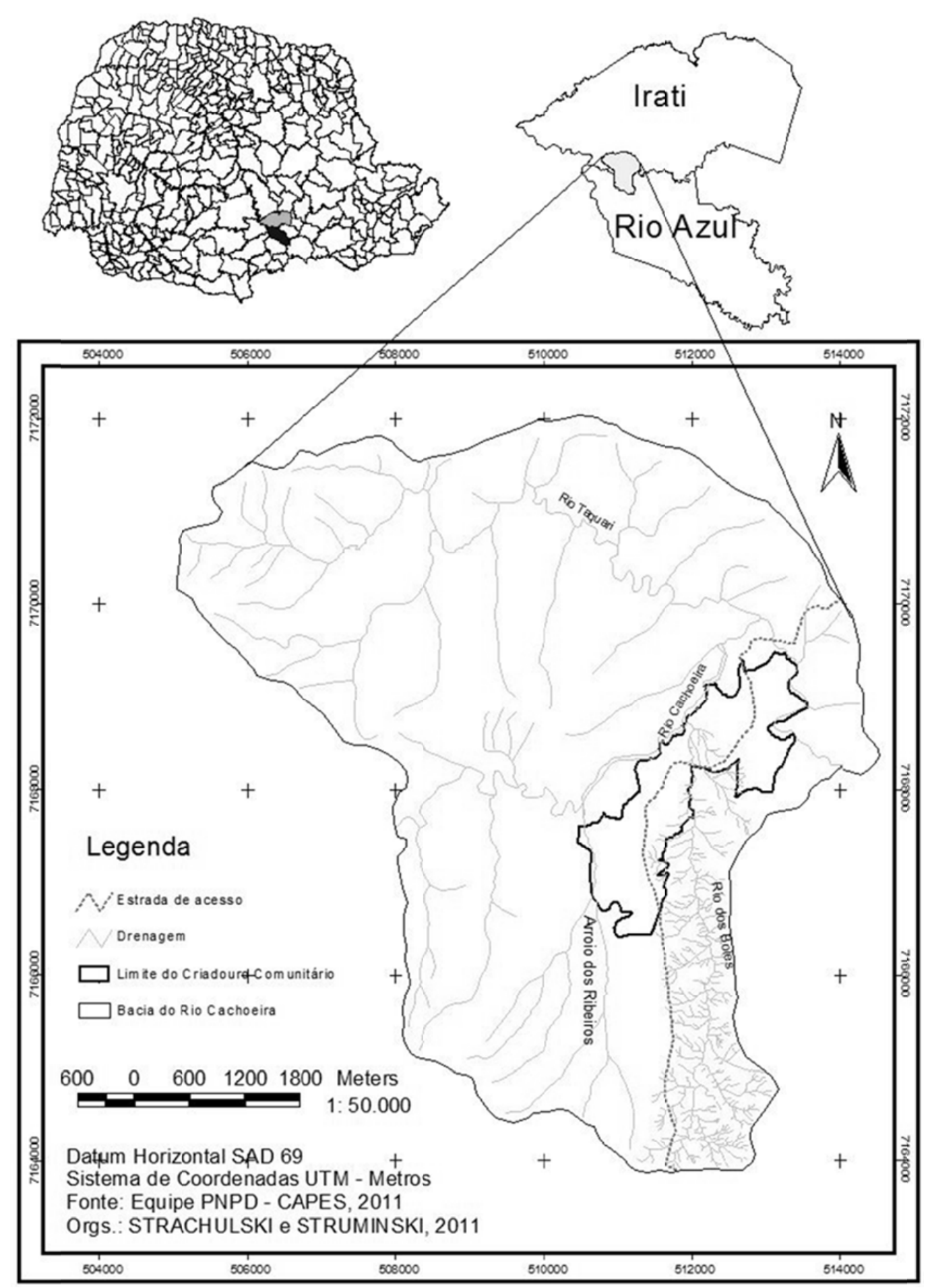


- Floresta Aluvial - nas margens dos rios da bacia do rio Iguaçu.

- Sistema Edáfico de Primeira Ocupação - várzeas úmidas nas planícies aluviais de rios da bacia do rio Iguaçu.

\subsection{A vegetação do faxinal Taquari dos Ribeiros}

Considerando que a formação florestal primária da área do faxinal em estudo era a Floresta Ombrófila Mista Montana, constatou-se que a interferência humana criou um mosaico de formações secundárias. A vegetação secundária surge imediatamente após a destruição da floresta, o corte seletivo de árvores ou o abandono de terrenos cultivados e pastos, sendo demonstrada pelo aparecimento de espécies típicas de estágios sucessionais secundários (capoeirinhas, capoeiras e capoeirões), que tendem a reconstituir as condições de microclima e solo favoráveis à instalação de outras espécies arbóreas do ambiente original, na forma de uma Floresta Secundária, caso não sejam novamente perturbados.

Também podem ser encontradas formações pioneiras em várzeas, que ocupam áreas reduzidas na região e que por condições de instabilidade no solo, o ocupam de forma pioneira, mas não necessariamente irão evoluir para os estágios florestais sucessionais.

Além destas formações naturais que ocupam 159,06 ha (Figura 2), existem, dentro do criadouro deste faxinal, áreas utilizadas para fins agropecuários como e reflorestamentos 5,36 ha e pastagens abertas ocupam 89,92 ha.

\subsection{Sistema Edáfico de Primeira Ocupação (Formações Pioneiras de campos úmidos ou várzeas)}

Segundo Veloso et al (1991), tal designação (formação pioneira) prende-se a uma tentativa de conceituar comunidades localizadas, sem ligá-las às regiões ecológicas clímaces, pois a vegetação que ocupa área com solo em constante rejuvenescimento nem sempre indica estar no caminho da sucessão para o clímax da região circundante (que é, no caso, a Floresta com Araucária) em função da instabilidade do solo.

Algumas formações pioneiras aparecem onde depressões do terreno permitem o acúmulo de matéria orgânica e água, tanto nas encostas, ou, mais comumente, nas margens dos rios. Por regularem o fluxo hídrico dos rios, as várzeas conservam a matéria orgânica acumulada. Normalmente, a água das inundações é absorvida pela várzea e evita que áreas contíguas sejam afetadas.

Porém, devido ao uso dessas áreas como pastagens, já não podem ser encontrados remanescentes de várzeas com aspecto primário nos trechos existentes dentro do faxinal. Os remanescentes existentes ocupam áreas planas sujeitas a inundações que foram modeladas pelos rios locais.

Outro aspecto importante relacionado à biodiversidade de ambientes úmidos 
Figura 2 - Vegetação do criadouro comunitário do faxinal Taquari dos Ribeiros, Rio Azul - PR

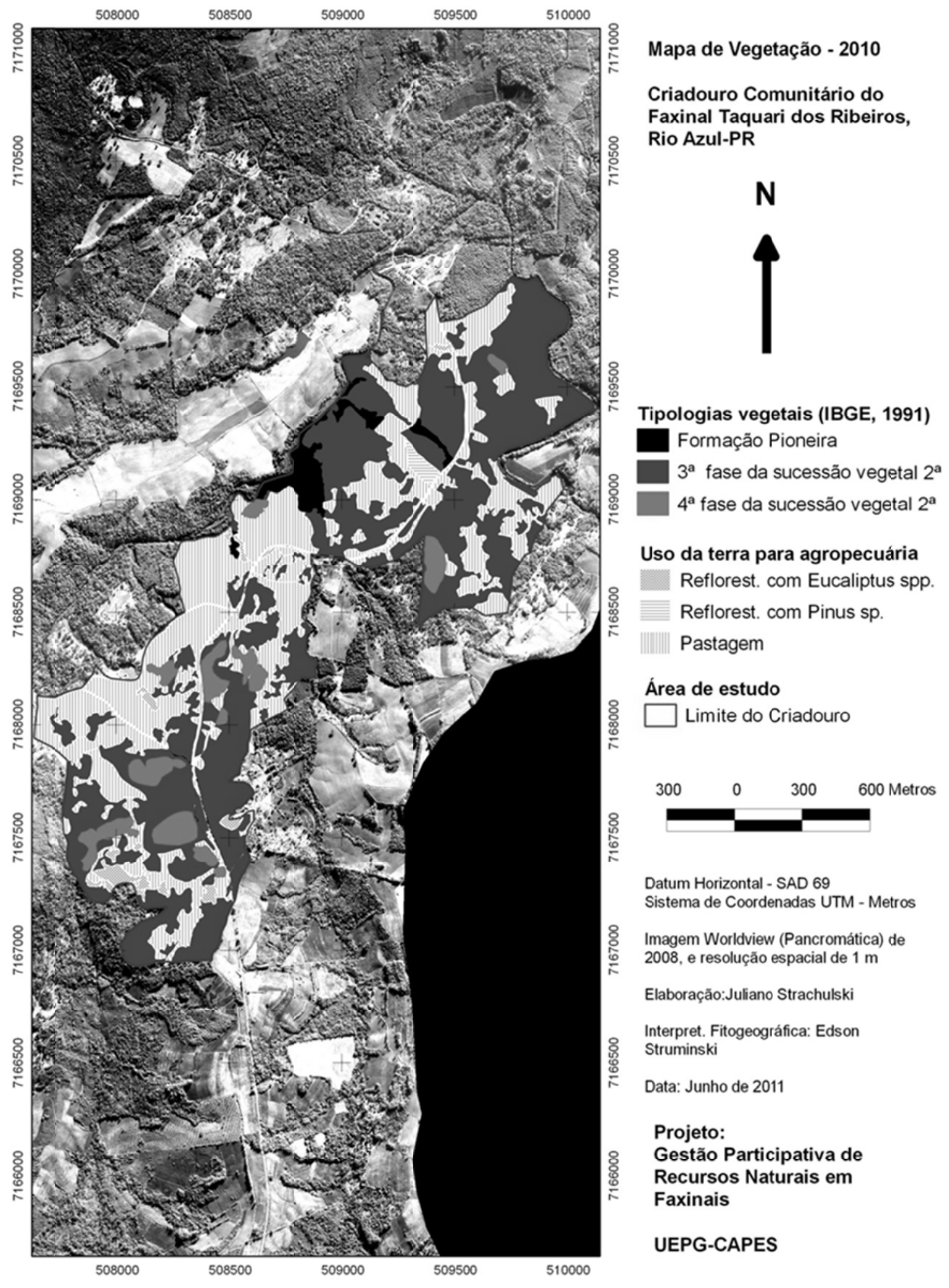


como várzeas, levantado por Struminski e Lorenzetto (2000), é que existe uma correlação importante entre a ocorrência da fauna e remanescentes vegetais (fragmentos) úmidos. Existe possivelmente um significativo número de espécies endêmicas ou restritas a esse tipo de ambiente. No entanto, o uso dessas áreas como pastagem por animais como porcos ou vacas pode promover a contaminação desse ecossistema com sementes de pastagem além de deslocar a fauna autóctone.

Conforme a Figura 2, no mapeamento realizado para o criadouro do faxinal, as formações pioneiras ocupam área de 6,63 ha ou 2,6 \% do perímetro estudado.

\subsection{Sistema de Vegetação Secundária no faxinal Taquari dos Ribeiros}

a) $1^{\mathrm{a}}$ e $2^{\mathrm{a}}$ fase de sucessão secundária

Os terrenos abandonados, após a instalação inicial de gramíneas, pteridófitas, ciperáceas e asteráceas, são ocupados normalmente por espécies arbustivas pioneiras muito características, com 2 a 3 metros de altura. É a chamada "capoeirinha". Segundo o Sistema do IBGE, essas duas situações, a capoeirinha herbácea inicial e a arbustiva representam o primeiro e segundo estágios iniciais da sucessão florestal, sendo constituídas por número reduzido de espécies dos gêneros Baccharis, Eupatorium, Vernonia, Vernonanthura e Campovassourea, as chamadas "vassouras" (RODERJAN E STRUMINSKI, 1992) que dão ao local inicialmente aparência de "campo sujo" passando posteriormente a ocupar de forma densa todo o terreno até onde podem, por um período que em média não ultrapassa 10 anos. Devido ao uso intensivo e valorizado da terra no faxinal, esse tipo de vegetação é facilmente convertido em área construída, pastagem ou reflorestamentos, sendo encontrado apenas de forma residual e temporária, não aparecendo na escala adotada no mapa.

b) $3^{\text {a }}$ fase de sucessão secundária

Os estágios médios ou avançados da vegetação secundária (capoeiras, capoeirões) aparecem quando os estágios sucessionais iniciais não são perturbados, por intermédio do aparecimento de espécies arbóreas que formarão um primeiro dossel florestal. Porém, outra forma mais provável do aparecimento dos estágios florestais médios ou avançados se dá no caminho inverso, pelo corte seletivo e retirada das árvores de maior porte que formam o dossel florestal primário, com o consequente empobrecimento (e aumento da luminosidade) da antiga floresta, resultado da extração seletiva de espécies florestais de maior valor comercial. Neste momento, o excesso de luz leva ao aparecimento destas capoeiras, com espécies arbóreas geralmente heliófilas de ciclo de vida curto (cerca de 20 anos) e rápido crescimento, que formam associações densas e mais heterogêneas que as capoeirinhas, correspondentes à terceira fase de sucessão secundária, com árvores em torno de $8 \mathrm{~m}$ de altura e diâmetro à altura do peito (DAP) em torno de $50 \mathrm{~cm}$.

Nas capoeiras podem ser observadas, entre outras: guabiroba (Campomanesia xanthocarpa), cedro (Cedrella fissilis), erva-mate (Ilex paraguariensis), canela guaicá (Ocotea puberula), aroeira (Schinus terebinthifolius), mamica-de-porca (Zanthoxyllum rhoifolia), 
leiteiro (Sapium glandulosum), capororocão (Myrsine umbellata), capororoquinha (Myrsine ferruginea), carvalho-brasileiro (Roupala brasiliensis), espinheira-santa (Maytenus ilicifolia), araçá (Psidium cattleianum). A palmeira-jerivá (Syagrus romanzoffiana) sobressai-se pelo perímetro à altura do peito (PAP) sensivelmente maior. A bracatinga (Mimosa scabrella) pode aparecer em porções iluminadas desses ambientes e a conífera Podocarpus lambertii (pinho-bravo) é a espécie com maior valor de importância destes remanescentes (FLORIANI, 2008).

Na área estudada, as capoeiras são as formações mais comuns, ocupando área de 138,73 ha ou $54,54 \%$ do criadouro do faxinal.

c) $4^{\mathrm{a}}$ e $5^{\mathrm{a}}$ fase de sucessão secundária

O estágio sucessional seguinte mais avançado (capoeirão) caracteriza-se pelo nítido aparecimento de dois estratos florestais, sendo que os estratos superiores podem ser inclusive dominados pelo Pinheiro-do-Paraná (Araucaria angustifolia) se ele estiver presente no início da sucessão. Nos inferiores, aparecem espécies ombrófilas como a erva-mate (Ilex paraguariensis), ou exemplares jovens que irão disputar a avidamente a luz com o pinheiro, como o cedro (Cedrella fissilis), a canjerana (Cabralea canjerana), lauráceas e mirtáceas, preparando o terreno para o estágio final (Floresta Secundária).

Estudos em ambientes similares indicam que o vassourão branco (Piptocarpha angustifolia) avança até os capoeirões, sendo a família Asteraceae a mais importante da associação, quando o pinheiro está ausente. Além dela, destacam-se Lauraceae, Salicaceae e Aquifoliaceae (LONGHI; STRUMINSKI; SESSEGOLO, 1994).

Para Tiepolo et al. (1998), as árvores com copas maiores e mais densas propiciam um ambiente interno mais úmido e de menor intensidade luminosa, surgindo espécies adaptadas a essa situação como bromeliáceas e orquidáceas, além da intensificação de pteridófitas arborescentes (xaxins).

Na área estudada, os capoeirões aparecem em manchas de 13,70 ha ou 5,31 \% da área do criadouro do faxinal, envolvidos por formações de capoeiras.

O estágio sucessional mais avançado, a floresta secundária, só virá a ocorrer quando, após cerca de 50 anos, puderem ser distinguidos dois estratos arbóreos e um terceiro em formação. Nele existirá ainda um estrato herbáceo-arbustivo bem desenvolvido e bem distribuído, transparecendo um aspecto de equilíbrio dinâmico nesta formação. A composição da floresta será determinada pelas espécies dominantes da fase anterior (KUNIYOSHI, 1989), ou a partir do manejo seletivo de espécies da floresta primária, situação em que os exemplares mais jovens remanescentes da floresta original ocupam o dossel. Nas áreas antigamente ocupadas pela Floresta Ombrófila Mista, o pinheiro pode vir a ser a mais importante da associação quando está presente nas fases sucessionais anteriores.

\section{d) Uso da terra para agropecuária}

Apesar do caráter eminentemente florestal com o qual costuma se associar o criadouro dos faxinais, uma área significativa da área estudada está ocupada por usos que o sistema do IBGE classifica como associados à agropecuária. Assim sendo, pastagens 
abertas ocupam 89,92 ha ou 35,3 \% da área do criadouro do faxinal. Reflorestamentos com Pinus spp e Eucalyptus spp, espécies exóticas usadas para produção de madeira ou lenha, ocupam respectivamente 1,29 ha e 4,07 ha, no total, $2,1 \%$ do criadouro.

e) Síntese sobre a vegetação do criadouro

Conforme podemos verificar na Figura 3, a vegetação do criadouro do Faxinal Taquari dos Ribeiros apresenta, em sua maioria, apenas tipologias secundárias em estágios médios da Floresta Ombrófila Mista, sendo que essa floresta em estágio primário ou secundário avançado encontra-se, portanto, ausente da área do criadouro deste faxinal. Quase $60 \%$ do criadouro apresenta-se a forma da terceira e quarta fase sucessional secundária dessa floresta, sendo que a terceira fase (capoeira) representa a fisionomia florestal mais comum, com mais da metade da área do faxinal. Porém pastagens abertas em meio às áreas de capoeiras também mostram-se bastante comuns, sendo que mais de um terço do faxinal apresenta esta fisionomia.

Figura 3 - Distribuição da vegetação no criadouro do faxinal Taquari dos Ribeiros

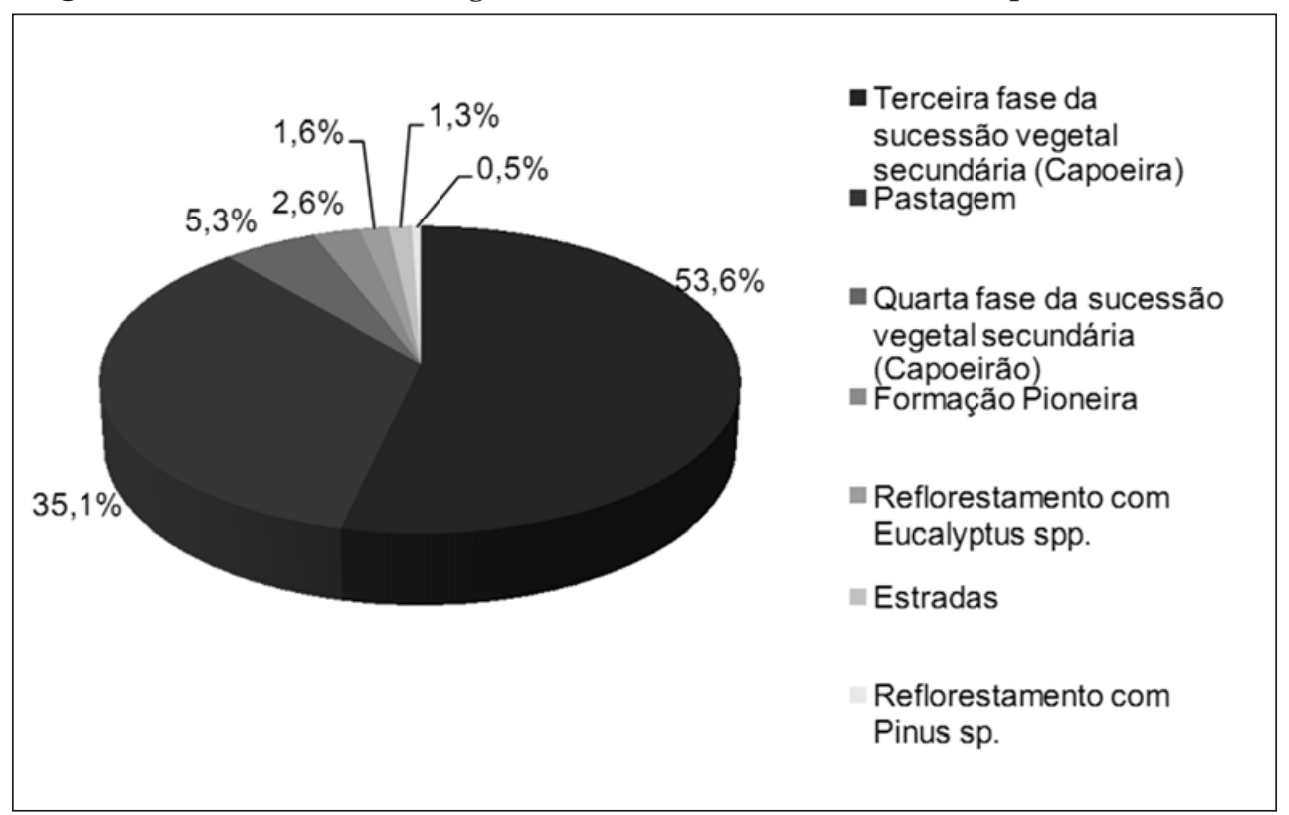

Fonte: Org.: Equipe PNPD - CAPES, 2011

\section{DIAGNÓSTICO AMBIENTAL: ANÁLISE DA FRAGMENTAÇÃO DA VEGETAÇÃO}

Além da distribuição da vegetação existente nas diferentes tipologias, importa saber como ela está agrupada, ou seja, entender sua fragmentação espacial. A partir dos dados provenientes do mapa de vegetação do criadouro do Faxinal Taquari dos Ribeiros, também foi possível realizar um diagnóstico ambiental mais refinado em relação à qualidade ambiental da vegetação local e fazer uma estimativa quanto à sua sustentabilidade, ou em outras palavras, à sua resiliência em função das alterações já verificadas. 
A base teórica do estudo de fragmentação florestal é oriunda da teoria de bigeografia de ilhas oceânicas. Rodrigues (1998), aliás, lembra que essas áreas têm sido chamadas de fragmentos para salientar que elas não mais se comportam como florestas intactas. Este autor entende que a importância do conhecimento sobre a fragmentação hoje é óbvia, pois em muitas paisagens, a esmagadora maioria das espécies está restrita aos fragmentos.

Na verdade tem se constado que a extinção de espécies é fortemente dependente da área do fragmento, bem como do número de espécies presentes. Quanto maior é o número de espécies em relação à capacidade de suporte da área, maior é a extinção de espécies por unidade de tempo. Por este motivo, Terborgh e Winter (1980) consideram que reservas maiores podem ser mais eficientes para a conservação da biodiversidade.

Viana et al (1992) também concordam que com a redução do número e do tamanho dos fragmentos, ocorrem perdas na diversidade natural em função do desaparecimento físico de indivíduos (árvores ou animais) ou declínio gradual das populações, que tendem a conter poucos indivíduos e muitas espécies raras. Os mesmos autores, estudando fragmentos na região de Piracicaba (SP), consideraram que áreas com menos de 10 ha apresentaram sérios indícios de não sustentabilidade, em função do alto percentual de redução da vegetação nativa, pequena área individual, forma alongada dos fragmentos, baixa frequência natural de muitas espécies, elevada densidade de cipós, árvores mortas e alta vulnerabilidade a perturbações antrópicas.

A importância do tamanho dos fragmentos para a conservação da biodiversidade na forma de reservas também tem suscitado discussões. Fernandez (1997), revisando a literatura disponível, concluiu que reservas próximas umas das outras e regulares são princípios quase consensuais hoje na conservação. Entretanto, constatou que existe polêmica quanto aos princípios que consideram que reservas maiores são melhores que várias pequenas de tamanho equivalente ou que reservas ligadas por corredores são melhores que outras sem essas conexões.

No primeiro caso, várias reservas pequenas poderiam ser realmente melhores que uma grande, caso o habitat fosse muito heterogêneo antes da fragmentação. Neste caso, as listas de espécies das reservas pequenas dariam número maior que a da reserva grande. Para ambientes mais homogêneos, as reservas grandes parecem ser mais indicadas.

No segundo caso, existe a contestação de que corredores podem ser uma faca de dois gumes, pois permitem tanto a passagem de indivíduos das populações quanto do fogo, epidemias ou espécies invasoras.

Neste sentido, é necessário considerar alguns fatores, como as condições ambientais da região, barreiras antrópicas, a existência de rotas de migração natural ou de simples circulação, a existência de zonas de contato ou tensão ecológica entre dois ambientes distintos.

a) Avaliação da fragmentação florestal no Faxinal Taquari dos Ribeiros

A Tabela 1 mostra uma análise da fragmentação da vegetação secundária existente no Faxinal Taquari dos Ribeiros, tendo por base o mapa de vegetação elaborado para o criadouro. 
Tabela 1 - Agrupamento de 36 fragmentos de vegetação natural (com exclusão de Pinus, Eucalipto e pastagens) e suas áreas no criadouro do faxinal Taquari dos Ribeiros

\begin{tabular}{|c|c|c|c|}
\hline Fragmento & Área (ha) & Fragmento & Área (ha) \\
\hline 1 & 25,93 & 19 & 0,97 \\
\hline 2 & 0,58 & 20 & 16,96 \\
\hline 3 & 9,00 & 21 & 11,23 \\
\hline 4 & 27,03 & 22 & 0,44 \\
\hline 5 & 0,30 & 23 & 0,10 \\
\hline 6 & 0,41 & 24 & 3,84 \\
\hline 7 & 0,64 & 25 & 5,85 \\
\hline 8 & 0,71 & 26 & 0,17 \\
\hline 9 & 0,28 & 27 & 0,31 \\
\hline 10 & 19,42 & 28 & 0,21 \\
\hline 11 & 0,41 & 29 & 0,12 \\
\hline 12 & 0,55 & 30 & 0,08 \\
\hline 13 & 0,48 & 31 & 1,81 \\
\hline 14 & 0,81 & 32 & 3,34 \\
\hline 15 & 2,58 & 33 & 0,22 \\
\hline 16 & 2,73 & 34 & 15,65 \\
\hline 17 & 0,25 & 35 & 4,02 \\
\hline 18 & 0,84 & 36 & 0,79 \\
\hline \multicolumn{3}{|l|}{ TOTAL } & 59,06ha \\
\hline
\end{tabular}

Fonte: Org.: Equipe PNPD - CAPES, 2011

Alguns dos polígonos das diferentes tipologias apresentam continuidade estrutural entre si, ou seja, pode ocorrer que, por exemplo, formações pioneiras formem "corredores florestais", entre capoeiras, as quais podem conter um núcleo com adensamento florestal (capoeirões). Na prática, isso significa que os 60 polígonos identificados em imagens aéreas puderam ser agrupados em 36 fragmentos contínuos, além de alguns fragmentos isolados.

Essa tabela mostra que apenas foram encontrados 6 agrupamentos que ultrapassam a área de 10 ha, que a literatura considera como mínima para a sustentabilidade de um fragmento florestal. Os demais fragmentos desempenham, provavelmente, mero 
papel de corredores ou "trampolins ecológicos" entre os fragmentos maiores. Por outro lado, o mapeamento aqui apresentado sofre limitações em função do recorte geográfico adotado, o qual abrange apenas a área do criadouro do faxinal. Eventualmente alguns fragmentos aparecem "recortados", por excederem a área do criadouro, o que significa que podem apresentar área maior. Mesmo assim, a análise visual do entorno do faxinal confirma a existência de um padrão regional altamente fragmentado para a vegetação, $\mathrm{o}$ que significa que o faxinal pode ser considerado como uma amostra válida do comportamento do uso do solo para a região, ou seja, muitos fragmentos de pequeno tamanho.

Também a forma dos fragmentos, extremamente irregular, contribui para a redução da capacidade de regeneração da floresta, pelo excesso de luminosidade presente no patamar do sub-bosque.

b) Conservação e uso da floresta no faxinal

O sub-bosque é um indicador importante da qualidade de uma área florestal porque mostra a capacidade de regeneração da floresta e a presença ou ausência de interferências na sucessão vegetal para estágios mais avançados.

A condição dos sub-bosques existentes no criadouro do faxinal é variável. Na maioria dos casos, constatou-se uso intenso por animais com bosqueamento (simplificação) do sub-bosque, o que reduz a regeneração natural (Figuras 4 e 5). Foi possível constatar sobrepastagem, inclusive já gerando uma simplificação da cobertura arbórea (Figura 6) por seleção negativa, sendo, portanto, um estágio secundário florestal ainda mais simplificado que o normal (uma Floresta Ombrófila Mista 'aberta') ${ }^{3}$, com predomínio de poucas espécies, como Podocarpus lambertii. Em casos mais raros, foram encontradas áreas de pousio sem uso do sub-bosque por animais (Figura 7). Também verificou-se pastagem em áreas de preservação permanente (margem de rios).

Figura 4 - Área com subosque simplificado por pastagem

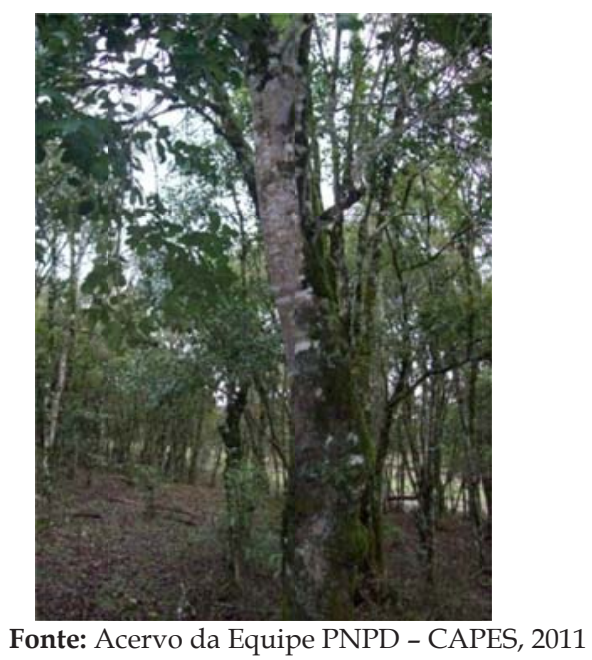

3 A Floresta Ombrófila Mista 'aberta' representa uma proposta de tipologia híbrida de classificação fitogeográfica, derivada das tipologias convencionais do IBGE, representando um ambiente simplificado desta floresta, com predomínio de poucas espécies e ausência de sub-bosque. 
Figura 5 - Animal pastando em sub-bosque

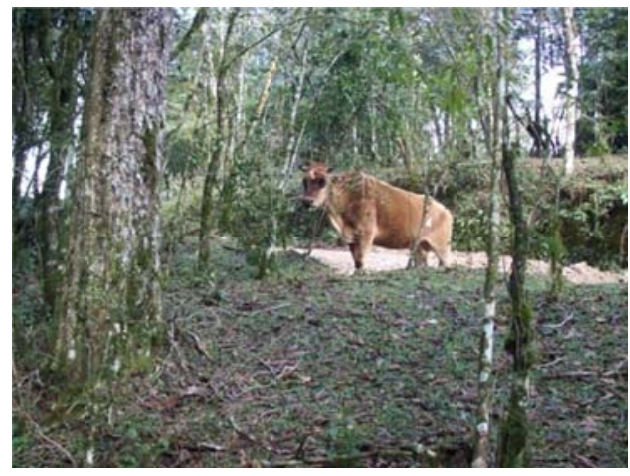

Fonte: Acervo da Equipe PNPD - CAPES, 2011

Figura 6 - Área com sub-bosque sobrepastado com predomínio de Podocarpus lambertii

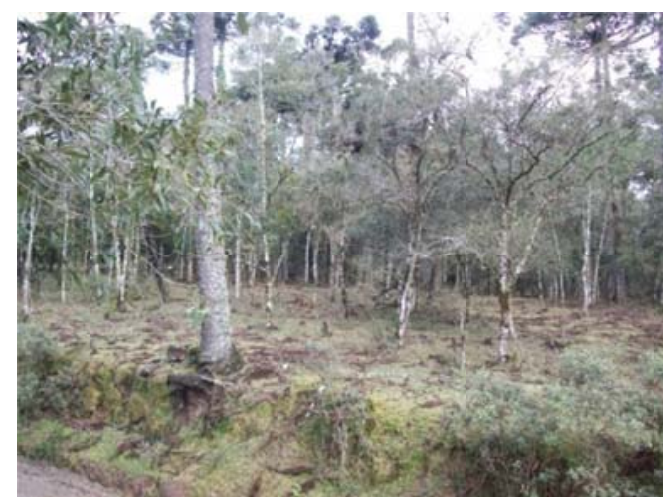

Fonte: Acervo da Equipe PNPD - CAPES, 2011

Figura 7 - Área com sub-bosque em regeneração

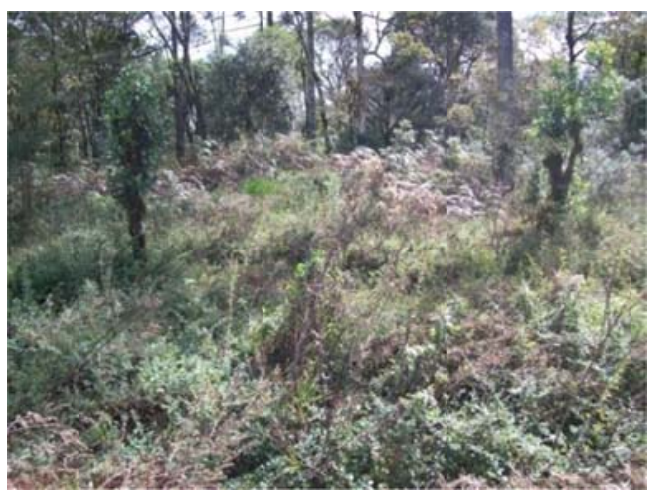

Fonte: Acervo da Equipe PNPD - CAPES, 2011

c) Uso da madeira

O uso das árvores para lenha no faxinal foi e continua sendo intenso. Inicialmente a madeira de melhor qualidade (pinheiro, imbuia etc) foi serrada para fins construtivos como no criadouro, conforme pode-se observar no local (Figuras 8 e 9) e por intermédio de evidências coletadas como troncos remanescentes (Figura 10) e nós de pinho que atestam corte de árvores de grande porte e de idade avançada. Os faxinalenses são conscientes 
da intensidade de corte, principalmente no período de formação do faxinal, quando a floresta era primária com abundância de espécies de alta qualidade para fins florestais, embora sempre atribuam "aos outros" (vizinhos) esse corte. No caso das terras convertidas para pastagem, houve remoção integral da floresta para abertura dos terrenos.

Atualmente a madeira segue sendo usada basicamente para lenha (secagem do fumo e usos domésticos). Alguns faxinalenses plantam eucalipto, pinus ou bracatinga para este fim, inclusive dentro do criadouro. Mas em alguns casos, já há compra de madeira de fora do faxinal devido à restrição de corte existente no criadouro por conta da fiscalização do estado. Existem reclamações contra a restrição ao corte de madeira dentro do criadouro, sugerindo que os moradores não conheçam as restrições da ARESUR.

O plantio e uso da erva-mate parece ser incipiente hoje no faxinal. Não foram encontradas áreas muito significativas desta cultura ou de manejo de nativas, embora existam erveiras manejadas.

Figura 8 - Construção em pinheiro

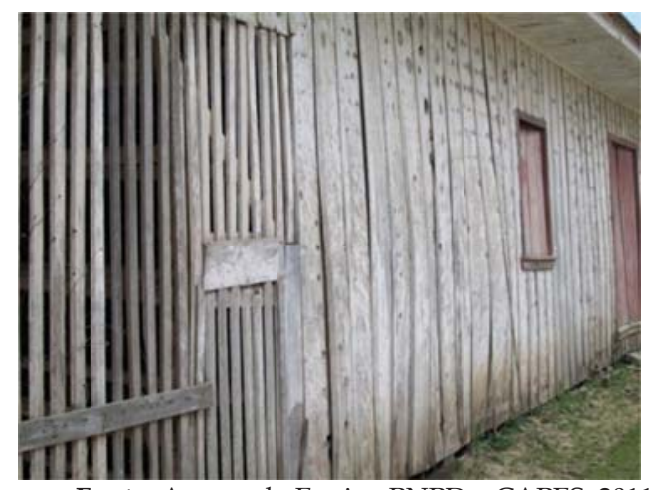

Fonte: Acervo da Equipe PNPD - CAPES, 2011

Figura 9 - Cerca de imbuia

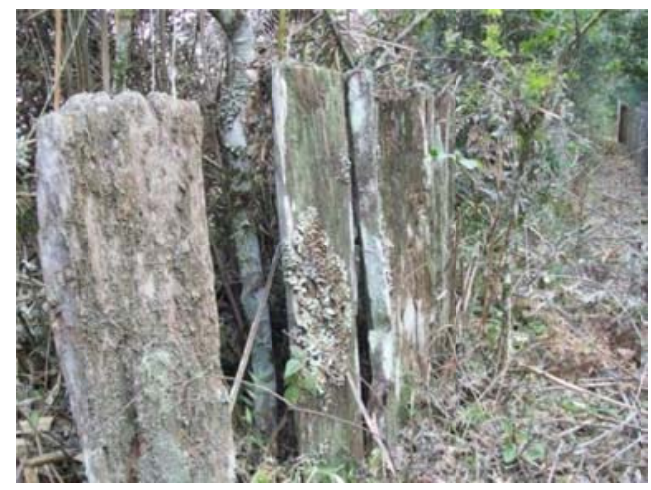

Fonte: Acervo da Equipe PNPD - CAPES, 2011 
Figura 10 - Tronco de imbuia cortado no criadouro do faxinal

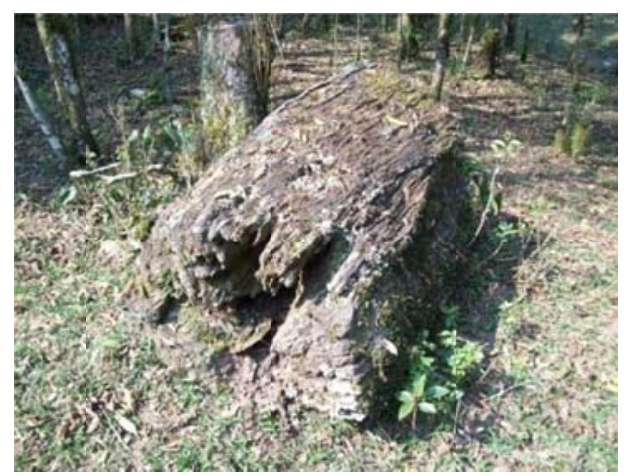

Acervo da Equipe PNPD - CAPES, 2011

d) Conhecimento sobre a biodiversidade florestal

De modo geral, as entrevistas com os faxinalenses mostraram que a maioria tem conhecimento escasso sobre a biodiversidade florestal do criadouro. Alguns ignoram, inclusive, que o uso de animais causa danos à regeneração das árvores. Uma notável exceção são os informantes Airton e Doraci Ribeiro (pai e filho), que demonstram não só conhecimento sobre a biodiversidade florestal, mas também sobre ecologia florestal, tendo identificado o fenômeno da simplificação da cobertura arbórea por seleção negativa (que podemos chamar aqui de Floresta Ombrófila Mista 'Aberta') inclusive identificando Podocarpus como indicador deste fenômeno.

\section{A VEGETAÇÃO DOS FAXINAIS, CONCEITOS MÚLTIPLOS E CONCLUSÕES DÍSPARES}

Em diferentes pesquisas em faxinais, aparecem termos diversos ou até mesmo inadequados do ponto de vista fitogeográfico, dificultando a compreensão a respeito do que os autores estão se referindo. Além disso, há uma vasta gama de conceitos sobre faxinais, a partir da fisionomia da vegetação presente neles. Tudo isso prejudica, de alguma forma, o diagnóstico e o correto planejamento territorial destas áreas, sua conservação ou manejo.

Por outro lado, foram encontradas algumas pesquisas que mostraram aspectos florestais de faxinais, mesmo que não focando particularmente neste sistema, mas que geraram conclusões neutras sobre os faxinais que mereceriam mais atenção.

Muitos autores consideram o faxinal como um sistema ambientalmente adequado pelo fato de estarem ocupados por populações tradicionais. Essa opinião foi endossada pelo Decreto Estadual n. ${ }^{\circ}$ 3.446/97, que criou as Áreas Especiais de Uso Regulamentado (ARESUR), em seu artigo $1^{\circ}$, parágrafo $1^{\circ}$, que define como Sistema Faxinal:

O sistema de produção camponês tradicional, característico da região Centro-Sul do Paraná, que tem como traço marcante o uso coletivo da terra para produção animal e a conservação ambiental. Fundamenta-se na integração de três componentes: 
a) produção animal coletiva, à solta, através dos criadouros comunitários; b) produção agrícola - policultura alimentar de subsistência para consumo e comercialização; c) extrativismo florestal de baixo impacto - manejo de erva-mate, araucária e outras espécies nativas (PARANÁ, 1997).

Oliveira (2008) igualmente afirma que o Sistema Faxinal constitui uma experiência de desenvolvimento sustentável de grande importância ecológica e histórica da região centro sul paranaense, constituindo parte significativa da cobertura florestal remanescente do Estado.

Para Novak e Fajardo (2008), as "matas limpas", onde se desenvolviam a erva-mate, as frutíferas silvestres, os pinheiros, algumas madeiras de lei e as gramíneas, foram um ótimo meio natural, denominado pela população de "caíva", para o desenvolvimento do criadouro comum do faxinal. A criação andava em meio a essa vegetação, que esses autores consideram como pouco densa (sic), sem dificuldade. O pastejo dos animais dentro dos ervais diminuía o serviço de limpeza (roçada) para os produtores. O meio era farto de alimentos silvestres (raízes, frutos, insetos etc.) e poupava os criadores do custo da alimentação.

Já para Muller (2006), os faxinais recebem este nome em função de um tipo específico de vegetação que crescia nesses locais, bons para se fazer vassoura (possivelmente as vassourinhas, espécies do gênero Baccharis, típica das capoeirinhas, ou seja, dos primeiros estágios sucessionais da vegetação secundária). Algumas pessoas entrevistadas por este autor rememoraram o tempo em que no faxinal pesquisado por ele, só havia "mato" e que os "italianos" quando ali chegaram modificaram toda a vegetação, retirando até o toco das árvores.

Mesmo assim, Antunes e Sochodolak (2010) consideram que a compreensão de tempo entre os antigos faxinalenses aponta para uma profunda ligação do homem com o natural, com a terra, com as árvores, com as águas, ou melhor, com a forma cíclica de ser nas florestas de araucárias. Mas segundo Thomaz (2007), o sistema faxinal representou apenas mais um dos tantos ciclos econômicos de exploração do Paraná, sendo hoje um sistema pelo qual famílias residem no local geração após geração, sob condições precárias, com base no extrativismo vegetal, agricultura convencional, conservação ambiental e auxílios governamentais.

Já para Löwen Sahr (2005), a conservação da biodiversidade ocorre, sobretudo, nas terras de criar (criadouros). É também nesse espaço que habitam os faxinalenses, que desenvolvem uma forte convivência e integração com o meio ambiente, além de desenvolverem culturas de extrativismo. Os animais buscam ali sua alimentação (frutos silvestres, folhas). Os faxinalenses extraem a erva-mate da Ilex paraguariensis e o pinhão da Araucaria angustifolia. Até há poucos anos, o beneficiamento da erva-mate era realizado nos próprios faxinais, desta forma, era comum se encontrar neles antigos barbaquás e carijós.

Porém, segundo Sampaio (2005) citado por Ferreira (2008), em alguns faxinais estudados, poucas seriam as árvores nativas de grande porte que restaram e os rios estariam assoreados por causa do desmatamento, pouco existindo de erva-mate porque as 
criações a comeram e a quantidade de pinheiro diminui, pois os cabritos ou outros animais se alimentaram dele, quando estava com pequeno porte.

Mesmo com essas mudanças, esta autora considerava que a "floresta densa" ainda estava presente em grande parcela desses faxinais, o que demonstraria a utilização sustentável dos recursos naturais no criadouro. Para um faxinal estudado pela autora, teria sido encontrada essa "floresta densa" cobrindo 66\% da área; "floresta limpa", em 12\%; e "campo" em 15\%.

Alguns autores ressaltam o aspecto de manejo pastoril dos faxinais. Para Machado (2008), faxinais são também chamados de "campos sujos", ou seja, pastagens com muitas árvores, enquanto que Sabourin (2008) refere-se a faxinais como "áreas de pasto" e Menezes (2009) considera faxinais como "cerrados em solo fraco para a lavoura, mas propícios para receber o gado com pouco trabalho". Já Klauberg et al (2010) citam o botânico Klein (1978), para quem a Floresta Ombrófila Mista divide-se em duas subformações: a Floresta dos Pinhais e a Floresta dos Faxinais, sendo esta uma área manejada.

Oliveira (2008) cita Chang (1988), para quem, etimologicamente, "faxinal" significa "mato ralo com vegetação variada" ou "braço de campo com árvores esguias" que penetra as matas. Para Carvalho (1984), também citado por esta autora, o termo faxinal provavelmente se originou de faxina, ou seja, limpeza sob o bosque que a criação solta promove.

De qualquer modo, para Sampaio (2005), também citado por esta autora, a cultura faxinalense teria uma visão diferenciada da "Mata com Araucária", com o uso sustentável da natureza dentro do criadouro comunitário, o que, como foi visto, é contestável. Segundo ele, o ambiente do faxinal apresenta, por si só, certa dificuldade de regeneração de espécies vegetais, por causa do sistema de criação de animais soltos. Mesmo assim, o autor considera que a história de faxinais estudados por ele demonstra a alta resiliência de seu sistema agrosilvopastoril.

Já para Hauresko (2008), atualmente, essas comunidades são responsáveis por contribuírem para a manutenção da paisagem florestal nativa do "Bioma Floresta com Araucária" e especialmente com um modo de vida tradicional de suas populações representado por sociabilidade particular, derivadas do uso comum da terra e das relações de parentesco. Mas para Furtado et al (2003) que analisaram 20 faxinais cadastrados pelo IAP em quatro municípios paranaenses, existe uma grande variação no ranking de qualidade dos faxinais quando se aplica uma análise mais apurada, havendo faxinais com alta qualidade enquanto há outros com baixa qualidade ambiental e problemas com os moradores.

Mesmo assim, para Löwen Sahr e Cunha (2005), tudo indicaria que o impacto ecológico do Sistema Faxinal seria muito menor do que o provocado pela agricultura moderna. Desta forma, o Sistema Faxinal, como exemplo especial de multifuncionalidade da agricultura, deveria ser abordado não apenas por critérios econômicos e produtivistas, mas principalmente pelo que significa em termos culturais e ambientais.

Mas a partir do estudo ecológico dos faxinais, torna-se possível vislumbrar melhor o efeito deste sistema no ambiente natural das florestas da região e buscar evidências sobre sua sustentabilidade. 
Thomaz (2007), que estudou a dinâmica do uso da terra e a degradação do solo em uma bacia hidrográfica em Guarapuava, percebeu que uma área com floresta secundária com 50 anos em um faxinal registrou 12,5 t/ha de deposição foliar, valor próximo ao encontrado em outros usos como capoeiras, uma vegetação secundária em estágio muito inferior do ponto de vista sucessional. Mas o que chamou a atenção nesse caso foi a variabilidade da cobertura de serrapilheira $(46,9 \%)$. Ou seja, no intervalo de confiança estimado, o valor ficou entre 9,2 t/ ha (equivalente a uma área secundária meramente em estágio inicial de sucessão) e 15,7 t/ ha; padrão que se deve ao desbaste realizado no interior dessa floresta. Algumas áreas não possuíam sub-bosque ou estrato herbáceo, ficando recobertas apenas com o dossel formado pelas araucárias ou por outras espécies. Isso certamente contribui para reduzir o adicionamento de serrapilheira ao solo da floresta; além disso, a distribuição da serrapilheira era irregular internamente.

Já Vibrans et al (2008), estudando a estrutura florestal em diferentes ambientes primários e secundários, observaram que em um faxinal, a Araucaria angustifolia se apresentava com maior número de indivíduos no estrato médio, ou seja, até $20 \mathrm{~m}$ de altura e sua posição fitossociológica relativa era de $4,11 \%$. Como a Araucaria originalmente dominava, de forma absoluta, o estrato das árvores emergentes com altura aproximada de 40 m e o estrato das Lauraceae e das Myrtaceae situava-se em altura média entre 25 a $30 \mathrm{~m}$, concluíram que houve alto grau de exploração dessas espécies ao longo do tempo. Estes autores comentaram que os fragmentos florestais dos faxinais foram intensamente alterados, ressaltando que muitos deles se encontram em estágio sucessional apenas médio ou avançado, apresentando ainda bosqueamento (simplificação) do sub-bosque, o qual privilegiou algumas espécies especialmente na fase adulta e eliminou jovens e componentes do sub-bosque. O conjunto de espécies dominantes representava agora um grupo de plantas adaptadas a ambientes alterados como os faxinais.

Finalmente, para Klein (1978), os fatores impactantes que reduzem, simplificam e alteram os remanescentes florestais existentes são: o corte seletivo de espécies, o fogo, o corte do sub-bosque, o pastoreio pelo gado e o avanço das fronteiras agrícolas e de reflorestamentos com espécies exóticas. A simplificação estrutural e florística dos remanescentes compromete a manutenção desses, reduz a biodiversidade autóctone, possibilita a invasão por espécies alóctones, ou ainda, provoca alteração da estrutura fitossociológica.

\section{CONCLUSÕES}

O mapeamento da vegetação do faxinal Taquari dos Ribeiros mostrou apenas formações secundárias em estágio médio (capoeiras). Em menor percentual, aparecem poucas manchas em estágio avançado (capoeirões) de sucessão natural da vegetação. Não foram encontrados estágios florestais primários dentro do criadouro do faxinal.

Também encontrou-se um uso bastante intenso (cerca de um terço do criadouro) para agropecuária (pastagens e, em menor grau, reflorestamentos) que seguramente pouco contribui para a conservação de áreas florestais no criadouro do faxinal. Caso 
a qualidade genética dos animais continue declinando neste faxinal (LEITE et al, 2009), é provável que as demais áreas de pasto ou capoeira sejam convertidas para reflorestamentos comerciais, com fins de produção de madeira, descaracterizando ainda mais este faxinal.

A capoeira, vegetação dominante no criadouro (mais de 50 \% da área total), é um estágio arbóreo apenas médio dentro da vegetação secundária, demandando algumas décadas para adquirir a condição de "floresta". A grande quantidade de capoeiras sugere o intenso empobrecimento que os remanescentes florestais primários sofreram na região.

Além disso, os fragmentos florestais são de pequeno tamanho e separados uns dos outros por áreas de pastagens, apresentando também evidências de bosqueamento (simplificação) do sub-bosque, o que permite o ingresso livre de animais em todas as áreas florestais.

Com isso, não foi possível encontrar nenhuma evidência, no presente estudo, de que o faxinal estudado seja sustentável do ponto de vista da manutenção da Floresta Ombrófila Mista. Essa sustentabilidade se mantém mais como potencial no criadouro em função da existência de algumas árvores porta-sementes e da conservação do solo em áreas sem sobrepastagem. Nas demais áreas (terras de plantar e sobrepastadas), ou a floresta já foi retirada ou encontra-se em estado de franca decadência.

Ampliando-se a análise, também não foi possível encontrar nenhuma evidência, tanto na literatura quanto no presente estudo, de que o "sistema faxinal", de forma genérica, terras de plantar mais criadouro, seja sustentável do ponto de vista da manutenção desta mesma floresta.

A pequena produção em aspectos ecológicos (exemplificada pela reduzida produção de serrapilheira) demonstra que o faxinal, apesar de ser um sistema onde a floresta representa o traço determinante, é também um sistema onde a floresta aparece como mero pano de fundo para o aparentemente pouco claro, desaparecimento dos faxinais, citado por muitos autores e explicado, em geral, por razões externas como a pressão do mercado imobiliário, da indústria madeireira, ou do agronegócio (em especial da indústria do fumo).

Porém, as evidências científicas coletadas diretamente pelos poucos estudos ecológicos realizados em faxinais, inclusive este, sugerem que a degradação das áreas florestais dos faxinais vem ocorrendo, em ritmo lento, mas contínuo, desde que este sistema foi implantado, há mais de um século, por intermédio da retirada seletiva de madeira e do bosqueamento. Uma das explicações para o desaparecimento dos faxinais poderia ser, então, o próprio manejo realizado pelos faxinalenses.

Isso sugere que a qualidade destas áreas florestais não justificaria a inclusão de faxinais como unidades de conservação (ARESUR), o que pode ser considerada uma decisão precipitada, considerando os poucos estudos existentes na época da criação desta modalidade de unidade de conservação, pois o extrativismo florestal não pode ser mais considerado de baixo impacto e a produção animal coletiva, à solta, com criadouros comunitários, é prejudicial ao sub-bosque florestal. 
Eventualmente, mesmo a manutenção destas áreas como ARESUR possa até ser prejudicial a esse sistema, pois o uso dessas áreas passa a ser limitado pela legislação florestal, sendo que os proprietários podem vir a ser obrigados a conviver com situações burocráticas para tentar, por exemplo, o licenciamento do corte de madeira, que podem até mesmo desconsiderar os usos tradicionais dos faxinais.

Mais interessante, neste caso, seria a criação de linhas de crédito, similares ao Pronaf, para atender diretamente aos produtores interessados em introduzir melhorias no sistema produtivo do faxinal. Um "Pronaf Faxinal" poderia atender especificamente aos moradores de faxinais e vinculá-los a uma assistência técnica, que introduzisse tanto melhorias genéticas nas diferentes criações animais (bovinos, equinos, suínos etc), quanto na parte florestal.

Para recuperar essas áreas e mantê-las dentro do sistema produtivo, sugere-se o plantio de espécies florestais com qualidade genética melhorada, que possuam valor comercial como erva-mate, bracatinga, espinheira-santa etc, que possam enriquecer o sub-bosque. Como manejo integrado das terras de plantar, sugere-se o uso de espécies para lenha com eucaliptos, grevílea, ou bracatinga, que podem ser intercaladas com os sistemas viários da região e não deveriam compor o criadouro.

Também é recomendável a implantação de uma "vizinhança permeável" com o plantio de frutíferas, consórcios agrosilviculturais já bem aceitos na região como feijão-milho-bracatinga, que podem beneficiar os animais além da melhoria da forma (arredondamento) dos fragmentos florestais, principalmente a partir das bordas voltadas para a face norte, mais sujeitas aos efeitos da luz e falta de umidade.

\section{REFERÊNCIAS}

ANTUNES, J e SOCHODOLAK, H. O faxinal e a narrativa trágica. Revista Tempo, Espaço e Linguagem (TEL), v.1, n.1, jan./jul. 2010, p.133-143.

BITTENCOURT SILVA, C. Uso e ocupação da terra na bacia hidrográfica do rio Cachoeira, Rio Azul/PR entre 1980 e 2008. Ponta Grossa: Trabalho de Conclusão de curso (Bacharel em Geografia). Universidade Estadual de Ponta Grossa, Departamento de Geociências. 2010.

FERNANDEZ, F. A. S. Efeitos de fragmentação de ecossistemas: a situação das unidades de conservação. In: Congresso Brasileiro de Unidades de Conservação. Anais... Curitiba: IAP/UNILIVRE, 1997. p. 48 -68.

FERREIRA, P. Estudo sobre os faxinais Lageado de Baixo e Lageado dos Mello - PR: a construção de conhecimento a partir da ecologia social como subsídio para um projeto de turismo comunitário. Dissertação (Mestrado) Ciências Sociais Aplicadas. Ponta Grossa: Universidade Estadual de Ponta Grossa, 2008.

FLORIANI, N. Relatório parcial do projeto de pesquisa “Gestão Participativa de Recursos Naturais em Faxinais". Relatório bolsista (PNPD/CAPES, 2008). Universidade Estadual de Ponta Grossa, Programa de Pós Graduação em Geografia, Mestrado em Gestão do Território. 2008.

FURTADO, E. M.; CHAVES NETO, A.; DOMINGUES, Z. H.; HOSOKAWA, R. T. Ranqueamento de faxinais do Estado do Paraná através da análise fatorial. Revista Ciências Exatas e Naturais. Irati, v. 5, n 1, Jan/Jun 2003.

HAURESKO, C. Entre tradição e modernidade: a casa de madeira do Faxinal Anta Gorda - PrudentópolisPR. In: SEMANA DE GEOGRAFIA, 16. Anais... Universidade Estadual do Centro-Oeste. Guarapuava/ Irati: 2008. n. 5, p. 15-26. 
KLAUBERG, C.; PALUDO, G. F.; BORTOLUZZI, R. L. C.; MANTOVANI, A. Florística e estrutura de um fragmento de Floresta Ombrófila Mista no Planalto Catarinense. Biotemas, Florianópolis, v. 23, n. 1, p. 3547, 2010.

KLEIN, R. M. Mapa fitogeográfico do Estado de Santa Catarina. In: Flora Ilustrada Catarinense. Itajaí: Herbário Barbosa Rodrigues, 1978.

KUNIYOSHI, Y. S. Reconhecimento de fases sucessionais de vegetação arbórea. In: SEMINÁRIO SOBRE AVALIAÇÃO E RELATÓRIO DE IMPACTO AMBIENTAL. Anais... Curitiba: FUPEF, 1989. p. 97-107.

LEITE, D. M. G., CHERUMBIM, A. A. e PEREIRA, J. M. A. Caracterização da Criação Animal em Sistema Faxinal. Revista Brasileira de Agroecologia, Cruz Alta, v. 4. n. 2. nov., 2009.

LONGHI, S. J., STRUMINSKI, E.; SESSEGOLO, G. Aspectos fitossociológicos da vegetação natural do Parque Municipal da Barreirinha. Curitiba: Trabalho apresentado nas disciplinas Ecologia Florestal e Fitogeografia do Curso de Pós-graduação em Engenharia Florestal - UFPR, 1994.

LÖWEN SAHR, C. L. Povos tradicionais e territórios sociais: reflexões acerca dos povos e das terras de faxinal do bioma da Mata com Araucária. In: SIMPÓSIO NACIONAL DE GEOGRAFIA AGRÁRIA. SIMPÓSIO INTERNACIONAL DE GEOGRAFIA AGRÁRIA, 2. JORNADA ARIOVALDO UMBELINO DE OLIVEIRA. Anais... Presidente Prudente: 11 a 15 de novembro de 2005.

LÖWEN SAHR, C. L., CUNHA, L. A. G. O significado social e ecológico dos faxinais: reflexões acerca de uma política agrária sustentável para a região da mata com araucária no Paraná. Emancipação, Ponta Grossa, v. 5, n. 1, p. 89-104, 2005.

MACHADO, P. P. O conflito do canudinho de Lages (1897). Estudos de Sociologia, Araraquara, v.13, n.24, p.65-78, 2008.

MENEZES, C. V. B. Religiões e práticas religiosas na região do Contestado (SC): os herdeiros de um mundo desencantado. São Paulo. Tese de doutorado em antropologia social na Universidade de São Paulo. 2009.

MULLER, D. Comunidade remanescente de quilombos de Morro Alto: uma análise etnográfica dos campos de disputa em torno da construção do significado da identidade jurídico-política de remanescentes de quilombos. Porto Alegre: Tese de Doutorado. Instituto de Filosofia e Ciências Humanas, UFRGS. 2006.

NOVAK, R.; FAJARDO, S. Desintegração e resistência do sistema faxinal em Itapará - Irati - PR. UNICENTRO - Revista Eletrônica Lato Sensu, Irati, 2008. p. 1-12.

OLIVEIRA, D. A. Faxinais no município de Prudentópolis - PR: perspectivas históricas. In: ENCONTRO REGIONAL DA ASSOCIAÇÃO NACIONAL DE HISTÓRIA, 11 - "Patrimônio Histórico no Século XXI". Anais... Jacarezinho: ANPUH/PR, 2008. p. 1 - 10.

RODERJAN, C. V., STRUMINSKI, E. Caracterização e proposta de manejo da Serra da Baitaca - Quatro Barras - Pr. Curitiba: FUPEF/FBPN, 1992. v.2.

RODRIGUES, E. Efeito de bordas em fragmentos de floresta. Cadernos da Biodiversidade. Curitiba: IAP, dez. 1998, v.1, n.2, p. 1-6.

SABOURIN, E. Multifuncionalidade da agricultura e manejo de recursos naturais: reflexão sobre alternativas a partir do caso do semi-árido brasileiro. Tempo da Ciência, Brasília, v. 15, n. 29. p. 57- 72, 2008.

STRUMINSKI, E.; LORENZETTO, A. Mapeamento da vegetação e avaliação ambiental da APA do rio Passaúna. Curitiba. Relatório de Pesquisa. 2000.

TERBORGH, J.; WINTER, B. Some causes of extinction. In: SOULE, M.E.; WILCOX, B.A. Conservation Biology: na evolutionary perspective. Massachussets: Sinauer, 1980. p. 119-133.

TIEPOLO, G., GATTI, G. A.; GATTI, A. L. Estudos fitossociológicos de duas fases sucessionais da vegetação arbórea do morro Anhangava. In: Projeto Anhangava. Curitiba: SEMA/IAP-GAIA, 1998. p. 17-26.

THOMAZ, E. L. Dinâmica do uso da terra e degradação do solo na bacia do rio Guabiroba - Guarapuava/ PR. Ra'ega, Curitiba, n. 13, p. 109-128, 2007. 
VELOSO, H. P.; RANGEL FILHO, A. L. R.; ALVES LIMA, J. C. Classificação da vegetação brasileira adaptada a um sistema universal. Rio de Janeiro: Fundação IBGE, 1991.

VIANA, V. M., TABANEZ, A. J. A.; MARTINEZ, J. L. A. Restauração e manejo de fragmentos florestais. In: CONGRESSO NACIONAL SOBRE ESSÊNCIAS NATIVAS, 2. Anais... São Paulo: IF, 1992. p. 400-406.

VIBRANS, A. C.; UHLMANN, A.; SEVEGNANI, L.; MARCOLIN, M.; NAKAJIMA, N.; GRIPPA, C. R.; BROGNI, E.; GODOY, M. B. Ordenação dos dados de estrutura da Floresta Ombrófila Mista partindo de informações do inventário florístico-florestal de Santa Catarina: resultados de estudo-piloto. Ciência Florestal, Santa Maria, v. 18, n. 4, p. 511-523, out.-dez. 2008.

<www.faxinaiswordpress.com>. Acesso em: 15 jun. 2011.

Recebido em 09/11/2011

Artigo aceito para publicação em 28/12/2012 